\section{UNIVERSITÄT}

\section{$D_{E} U_{S} I_{S} S_{E} B_{N} U^{R} G$}

Chair for Management and Energy Economics

Prof. Dr. Christoph Weber
Science

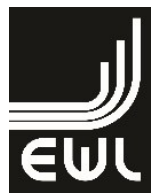

Chair for Management Sciences and Energy Economics University of Duisburg-Essen

EWL Working Paper No. [05/15]

\title{
The Role Of Heterogeneous Agents in Fuel Markets: Testing tales Of Speculators in Oil Markets
}

by

Andreas Fritz, Michael Stein, Christoph Weber

August 2015 


\title{
The Role of Heterogeneous Agents in Fuel Markets: \\ Testing Tales of Speculators in Oil Markets
}

\author{
by Andreas Fritz, Michael Stein, Christoph Weber
}

\begin{abstract}
This study investigates the role of heterogeneous agents in oil markets and tests tales of speculators in oil price formation. Results obtained from using a non-linear heterogeneous agent model suggest that oil market prices are driven by different groups of speculators, namely fundamentalists, chartists and the newly introduced contrarians. The latter enable us to disentangle stabilizing effects previously attributed solely to fundamentalists, and they are on average the most dominating group, whereas chartists exacerbate the huge price swings in 1990, 2008 and 2011. We also show how sensitive the model outcomes are to the specification of the fundamental value, what has strong economic implications.
\end{abstract}

Keywords: Energy

JEL-Classification: Q40

\author{
ANDREAS FRITZ \\ Chair for Management Science and Energy Economics, \\ University of Duisburg-Essen (Campus Essen) \\ Universitätsstr. 11, 45117 Essen \\ ++49 - (0)2 01 / 183-2713 \\ www.ewl.wiwi.uni-due.de \\ andreas.fritz@uni-due.de
}

The authors are solely responsible for the contents which do not necessarily represent the opinion of the Chair for Management Sciences and Energy Economics. 
The up and down of oil prices traditionally has received a lot of attention due to its impact on the global economy, and financial trading can be at least traced back to the mid 1980's making the oil market the most mature market among all energy carriers ${ }^{1}$. This makes it a natural choice of a laboratory to investigate trading behavior of market participants. We approach the topic from the behavioral side, thereby enhancing previous frameworks with additional strategies and various specifications of necessary inputs that are strongly driving the results.

Common to all commodities is an on-going process of financialization, where paper contracts on commodities are traded like assets. Due to this development there has been a wide debate on speculation esp. in oil markets and possibly spillover effects to other energy markets. (see Greenspan, 2004, Kaufmann and Ullman, 2009, Sornette et al. , 2009) The speculation argument stems from the observation that energy prices reached levels which cannot convincingly be explained by fundamental factors only. In particular the rise in oil prices between 2004 and 2008 has been in the focus since then. Where it has been popular among observers of the oil market that financial speculation has caused the surge, recent research indicates that also macroeconomic fundamentals can explain the price increase (see Alquist and Gervais, 2013, Fattouh et al. , 2013). But even if fundamental factors are indispensable for understanding oil price behavior it is also of interest how market participants process information of fundamental factors or fundamental values of commodities, how they act in trading, i. e. how they form heterogeneous beliefs and possibly drive prices by sentiment.

The behavioral finance literature has proposed various models to explain price dynamics which are not in line with the efficient market hypothesis (EMH, see Fama, 1970) or put differently, with investors who behave fully rational according to the efficient market hypothesis. Within the behavioral finance literature one strand of literature is focusing on bounded rationality of investors. Bounded rational agents are using rules of thumb for their (possibly homogeneous) expectations of future prices.

Among others Brock and Hommes (1998) drop the assumption of homogeneity of expectations among agents. Very popular in modeling such agent behavior is the class of heterogeneous agent models (HAM). The main idea behind models of heterogeneous agents is the existence of different groups of agents acting in markets. The behavior of different agents is then directly linked to the behavior of prices in these markets. The groups of agents differ among models in the literature, but most of them have in common that they try to include at least two groups of speculators along with the real economy.

E.g. the models used by Reitz and Westerhoff (2007) and Reitz and Slopek (2009) specify through a restriction of the switching function that at least $50 \%$ of the agents in the market are relying on fundamental trading factors. Here the real economy is not modeled directly but fundamental traders are somehow interpreted as acting similar to the real economy.

\footnotetext{
1 Crude oil covered 41\% of the world's demand for primary energy in 2011 IEA (International Energy Agency), 2013/footcit\}), and the International Energy Agency also claims that its importance will remain high even under different scenarios (New Policies and 450 Scenario).
} 
A second type of models includes the real economy via demand of consumers and supply of producers into the pricing equation. We are following the latter approach in this paper. Despite different considerations of the real economy in HAMs, all models have similar types of speculators in common. In this paper we make use of a heterogeneous agent model with three types of agents: fundamentalists, chartists and contrarians. In the literature, fundamentalists are also considered as (bounded) rational long-term investors (also called regressive, mean-reverting expectations fundamentalists) whereas chartists are (bounded) rational speculators (also called extrapolative expectations chartists or noise traders). There is no obvious best label for contrarians. They might be labeled as anti-rational or contraindicative speculators. The need for contrarians can be both explained empirically and theoretically. ${ }^{2}$

Fundamentalists trade according to a long-term fundamental value of crude oil. In this paper different model prices for the fundamental value are used as a proxy. This approach has two advantages. On the one hand the fundamental value is still an exogenous variable to the model allowing realized prices oscillating around that fundamental value. On the other hand using simply an endogenous fundamental value like historical mean or moving average (as in Ellen and Zwinkels, 2010) would contradict the logic underlying the trading behavior of fundamentalists because trading on a moving average as fundamental value is more similar to a chartist approach. The modelled fundamental value might not be the true value which makes fundamentalists bounded rational.

The behavior of chartists differs from the fundamentalists with respect to expectation building of prices and investment horizon. Chartists are only interested in one-period returns (short-term trading). This is also known in the literature as trend following Brock and Hommes (1998). Trend followers typically use simple trading rules based on limited information, making their behavior bounded rational. In this paper trend followers make use of a simple AR(1)-Process.

The third group of agents that we include is taking the beliefs of chartists as a contraindication and is building exact opposite expectations (see Lof (2015). To the best of our knowledge, this is the first study that provides an analysis of speculative behavior in the oil market employing three groups. Doing so, we are able to distinguish between stabilizing effects coming from fundamental considerations and of pure trading effects caused by contrarians.

In the model, agents do not have to stick to their behavior. They are allowed to switch between different trading strategies. This switching behavior causes a non-linear dynamic of oil prices and the interaction between stabilizing (fundamentalists, contrarians) and destabilizing (chartists) forces causes commodity price fluctuations. Thus, we use the evolutionary selection scheme introduced by Brock and Hommes (1997) and Brock and Hommes (1998) which has been widely used in finance models (see e. g. Boswijk et al. , 2007).

Our approach of a heterogeneous agent model to model price changes is well-grounded in previous research of different markets like exchange rates, commodities, oil and other financial assets. Among others, Reitz and Westerhoff (2007) estimate a model for agricultural commodities (e. g. wheat, soybean) whereas Reitz and Slopek (2009) fit a model to oil prices, with both studies providing

\footnotetext{
${ }^{2}$ For further explanations see notably Lof, 2015 and the references therein.
} 
evidence on heterogeneous agents driving prices. Ellen and Zwinkels (2010) also find significant impact of heterogeneous strategies in oil markets (WTI and Brent), but none of the mentioned papers includes three groups of agents or investigates the role of different fundamental price specifications.

We contribute to the literature in several ways. First, we are explaining the fluctuations observed in oil prices with the behavior of three groups of heterogeneous agents, including the new group of contrarians to disentangle stabilizing effects. Second, we gain insight in heterogeneous beliefs in oil markets by testing different specifications of expectation about fundamental prices and analyzing their influence on oil price dynamics. Third, we provide evidence on tales of speculators in the sense that we investigate whether different prominent phases of price dynamics where indeed driven by the expected group. The paper proceeds as follows. Section 2 develops our heterogeneous agent model. The empirical methodology and data are discussed in Section 3 . Section 4 provides the empirical results and section 5 concludes the paper.

\section{The heterogeneous agent model}

\subsection{Pricing equation}

We base our analysis on models in the style of Brock and Hommes (1997), Brock and Hommes (1998), Boswijk et al. (2007) and Ellen and Zwinkels (2010), use monthly oil prices and assume that the oil markets involve distinct categories of market participants. Movements in fuel prices are assumed to be influenced by financial investors, namely speculators (for example banks, pension funds, hedge funds, technical traders and index investors) and physical commodity market participants, namely producers and consumers with (physical) hedging needs (like oil companies, refineries, power utilities and physical traders). Even when trading in financial markets is conducted using paper contracts rather than physical barrels, the prices in financial and physical markets have to be considered as interconnected. Thus, we include the real economy in our model. ${ }^{3}$

In our model we first assume price changes $\mathrm{A} p_{t+1}$ from time $t$ to time $t+1$ to be caused by excess demand and include a noise term $\varepsilon_{t}$ allowing for stochastic shocks ${ }^{4}$

$$
\Delta p_{t+1}=\Phi\left[\widetilde{D}_{t}-\tilde{S}_{t}\right]+\varepsilon_{t}
$$

where $\widetilde{D}_{t}$ and $\tilde{S}_{t}$ are demand and supply respectively at time $t$. The parameter $\Phi$ accounts for an intensity of adjustment. The adjustment process itself can be considered as a trial and error process of market participants in order to find equilibrium market prices. Put differently, small parameter values for $\Phi$ imply sluggish behavior of market price movements. Aggregate net market demand $D_{t}$ stems from different sources $h$ of demand $D_{t}^{h}$. In our paper we assume three different groups of agents. One group of agents is forming regressive price expectations (fundamentalists) and one group of agents is forming extrapolative price expectations (chartists). Additionally we introduce the so-called contrarians as a third group, following an idea by Lof (2015) and transposing it to a commodity market.

\footnotetext{
${ }^{3}$ The analysis of the complex linkages between the sub-segments of markets is beyond the scope of this article. The interconnection of markets is shown for the case of crude oil among others in Kaufmann and Ullman, 2009.

${ }^{4}$ We assume an order-driven market. Another possibility would be to allow for a market maker in a quote-driven market in the price setting mechanism where excess demand and supply are fulfilled by the market maker. Because this assumes always sufficient market liquidity we do not adopt this possibility and believe that our tâtonnement process evolves to an equilibrium state.
} 
This last group believes the exact opposite of chartists. It is allowed for agents to switch between groups. Switching between groups is conducted by a switching rule as defined in Section 2.3. The market share of each group is denoted by $W_{t}^{h}$. Fundamentalists, chartists and contrarians are denoted by $f t, c t$ and $c s$. It is a natural assumption that demand from physical hedgers $D_{t}^{p}$ is always present in the market. Thus, demand is given by financial and physical traders. Analytically,

$$
D_{t}=W_{t}^{f t} D_{t}^{f t}+W_{t}^{c t} D_{t}^{c t}+W_{t}^{c s} D_{t}^{c s}+D_{t}^{p} .
$$

\subsection{Behavior of heterogeneous agents}

Each group of agents in the market forms their expectation differently, where $E_{t}^{h}\left(p_{t+1}\right)$ is the expectation for the price in the next period. Fundamentalists base their price expectations upon a fundamental analysis of future price developments, that is, they compare the current market price and the fundamental price. The exogenously generated fundamental price is denoted by $p_{t}^{*}$ and is available to all agents. In previous research not much interest was put in the specification of the fundamental price, and it was merely seen as sufficient to have some price that fundamentalists believe the fuel price to revert to, or at least a price the true price fluctuates around. In our model however we investigate how the use of different fundamental values $p_{t}^{*}$ affects the results.

Formally, the forecasting rule of fundamentalists relies on a weighted average of current prices $p_{t}$ and a long-term fundamental value $p_{t}^{*}$

$$
E_{t}^{f t}\left(p_{t+1}\right)=\left(1-b^{f t}\right) p_{t}+b^{f t} p_{t}^{*}
$$

Rearranging terms yields

$$
E_{t}^{f t}\left(p_{t+1}\right)=p_{t}+b^{f t}\left(p_{t}^{*}-p_{t}\right) .
$$

For values of $b^{f t}>0$ prices are driven back to the fundamental value. The demand of fundamentalists is linear and derives from their belief that the deviation from the fundamental value is transitory. Thus, net demand only depends on the mispricing of the asset and is expected to be higher the larger the current market price is away from its fundamental value.

$$
D_{t}^{f t}=a^{f t}\left(E_{t}^{f t}\left(p_{t+1}\right)-p_{t}\right), \quad a^{f t}>0
$$

The parameter $a^{f t}$ is assumed to be positive and measures how strong deviations factor into demand of fundamentalists. Fundamentalists' demand is positive when they see a current price lower than the fundamental value (the commodity being undervalued) and demand is negative when current prices are higher than the fundamental value.

The second group, the chartists, do not take the fundamental value into account and rely solely on past price movements using some functional form of technical analysis or other trend following mechanisms. Typically they expect a continuation of previous trends, formalized as

$$
E_{t}^{c t}\left(p_{t+1}\right)=p_{t}+b^{c t}\left(p_{t}-p_{t-1}\right) \text {. }
$$

For values of $b^{c t}>0$ chartists are amplifying price trends. From equation (7) it is clear that the process for trend estimation of the speculators is based on the extrapolation of past price movements, which 
is simple enough to be adapted by a lot of market participants. Chartists' net demand can be specified as

$$
D_{t}^{c t}=a^{c t}\left(E_{t}^{c t}\left(p_{t+1}\right)-p_{t}\right), \quad a^{c t}>0 .
$$

The demand of chartists is positive when they expect prices to increase in the next period and negative in the opposite case.

For the third group of agents, the contrarians, it is assumed that their expectations are based on a belief opposite to the beliefs of chartists. Accordingly, they also consider past price movements but expect a reversal of the previous trend, formalized as

$$
E_{t}^{c s}\left(p_{t+1}\right)=p_{t}+b^{c s}\left(p_{t}-p_{t-1}\right)
$$

with the parameter $b^{c s}$ expected to be negative. Thus, contrarians show stabilizing behavior and since we allow for different values of $b^{c t}$ and $b^{c s}$, the impact of both groups can be different. Demand for contrarians is defined analogously to equation (7) for chartists, such that the demand of contrarians is positive when they expect prices to be lower in the next period and vice versa:

$$
D_{t}^{c s}=a^{c s}\left(E_{t}^{c s}\left(p_{t+1}\right)-p_{t}\right), \quad a^{c s}>0
$$

\subsection{Switching mechanism}

The real world is complex and thus agents cannot be confident that their forecasting rules are true. They will thus evaluate the performance of the corresponding trading strategies and this is mimicked by computing past profitability or forecasting errors. After evaluation, agents will adjust their behavior to the most profitable forecasting rule. Therefore, agents are allowed to switch between the groups depending on the observed profitability. We assume that this forecasting performance translates into profits given that investors trade on their respective strategies. The switching mechanism between the three groups is based on Brock and Hommes (1997) and Brock and Hommes (1998) who model the weights $W_{t}^{h}$ as a function of past performance in a discrete choice model with multinomial logit probabilities

$$
W_{t}^{h}=\frac{\exp \left(\gamma^{h} \pi_{t}^{h}\right)}{\sum_{i} \exp \left(\gamma^{i} \pi_{t}^{i}\right)} \quad h, i \in\{f t, c t, c s\},
$$

where $\pi_{t}^{h}$ is the performance measure of group $h$ at time $t$. When the performance of one group is better compared to the other group, the fraction $W_{t}^{h}$ increases compared to the fraction of the others. The parameter $\gamma^{h}$ is often called intensity of choice in the literature and measures the reaction intensity to performance of the forecasting rules. ${ }^{5}$ Note when $\gamma^{h}=0$ then the fraction is equally distributed as $1 / \mathrm{H}$ which means that there are always $33 \%$ fundamentalists, $33 \%$ chartists and $33 \%$ contrarians in the market with no switching between the groups. With $\gamma^{h}=\infty$ all agents adopt instantaneously the most profitable trading rule, such that $W_{t}^{h}$ is either 1 or 0 . Economically speaking, agents behave rational and use the optimal forecasting rule in each period.

\footnotetext{
${ }^{5}$ Lof, 2012 is using an idea that the intensity of choice parameters are not held constant which means that agents might have different threshold levels over time before adopting a strategy. Since we want to primarily investigate agents' behavior to different fundamental values of oil we do not use this idea in this article and leave it for future research.
} 
Rewriting

equation

(10) for the share of fundamentalists yields

$$
W_{t}^{f t}=\frac{1}{1+\exp \left(\gamma^{c t} \pi_{t}^{c t}-\gamma^{f t} \pi_{t}^{f t}\right)+\exp \left(\gamma^{c s} \pi_{t}^{c s}-\gamma^{f t} \pi_{t}^{f t}\right)}
$$

For the sake of simplicity we assume that $\gamma^{f t}=\gamma^{c t}=\gamma^{c s}$. Thus equation (11) simplifies to

$$
W_{t}^{f t}=\frac{1}{1+\exp \left(-\gamma\left(\pi_{t}^{f t}-\pi_{t}^{c t}\right)\right)+\exp \left(-\gamma\left(\pi_{t}^{f t}-\pi_{t}^{c s}\right)\right)} .
$$

Analogously,

rewriting

equation

(10) for the share of chartists and assuming that $\gamma^{f t}=\gamma^{c t}=\gamma^{c s}$ yields

$$
W_{t}^{c t}=\frac{1}{1+\exp \left(-\gamma\left(\pi_{t}^{c t}-\pi_{t}^{f t}\right)\right)+\exp \left(-\gamma\left(\pi_{t}^{c t}-\pi_{t}^{c S}\right)\right)}
$$

Since the fractions of all agents sum up to one, the share of contrarians is obtained easily as $W_{t}^{c s}=$ $1-W_{t}^{f t}-W_{t}^{c t}$.

In our model we relate the difference of the fitness measures of two groups, e. g. $\pi_{t}^{f t}-\pi_{t}^{c t}$ as in equation Fehler! Verweisquelle konnte nicht gefunden werden., to the sum of the absolute values of these fitness measures, e. g. $\left|\pi_{t}^{f t}\right|+\left|\pi_{t}^{c t}\right|$ for these two groups as in Ellen and Zwinkels (2010). Using this relative performance measure the parameter $\gamma^{h}$ becomes comparable across our different specifications of the fundamental value. Thus, equation Fehler! Verweisquelle konnte nicht gefunden werden. yields

$$
W_{t}^{f t}=\frac{1}{1+\exp \left(-\gamma\left(\frac{\pi_{t}^{f t}-\pi_{t}^{c t}}{\left|\pi_{t}^{f t}\right|+\left|\pi_{t}^{c t}\right|}\right)\right)+\exp \left(-\gamma\left(\frac{\pi_{t}^{f t}-\pi_{t}^{c s}}{\left|\pi_{t}^{f t}\right|+\left|\pi_{t}^{c s}\right|}\right)\right)} .
$$

The weights for chartists are straightforward derived using equation (13).

The fitness of the agents' strategies is evaluated by computing the sum of squared forecasting errors given past realizations. Forecasting errors of all groups are thus assessed using

$$
\pi_{t}^{h}=-\sum_{d=1}^{D}\left(E_{t-d-1}^{h}\left(p_{t-d}\right)-p_{t-d}\right)^{2} .
$$

Using equations (4), (6) and (8) we obtain for the agent specific fitness measures

$$
\begin{aligned}
& \pi_{t}^{f t}=-\sum_{d=1}^{D}\left(-b^{f t}\left(p_{t-d-1}-p_{t-d-1}^{*}\right)-\Delta p_{t-d}\right)^{2} \\
& \pi_{t}^{c t}=-\sum_{d=1}^{D}\left(-b^{c t}\left(p_{t-d-1}-p_{t-d-2}\right)-\Delta p_{t-d}\right)^{2} \\
& \pi_{t}^{c s}=-\sum_{d=1}^{D}\left(b^{c s}\left(p_{t-d-1}-p_{t-d-2}\right)-\Delta p_{t-d}\right)^{2}
\end{aligned}
$$




\section{$2.4 \quad$ Real economy}

We follow Brock and Hommes (1997) as well as Ellen and Zwinkels (2010) and include the real economy in the model since physical contracts of crude oil are traded besides financial contracts. The net demand is again a linear function of the price ${ }^{6}$

$D_{t}^{p}=a^{p}+b^{p} p_{t}(19)$ With $a^{p}$ an exogenously given net demand level, resulting e.g. from an excess in hedging demand from oil consumers relative to oil producers.

\subsection{Solution of the model}

Inserting everything step by step starting with equation (1) yields

$$
\Delta p_{t+1}=\Phi\left[W_{t}^{f t} D_{t}^{f t}+W_{t}^{c t} D_{t}^{c t}+W_{t}^{c s} D_{t}^{c s}+D_{t}^{p}-S_{t}\right]+\varepsilon_{t} .
$$

Replacing real supply and demand

$$
\Delta p_{t+1}=\Phi\left[W_{t}^{f t} D_{t}^{f t}+W_{t}^{c t} D_{t}^{c t}+W_{t}^{c s} D_{t}^{c s}+a^{p}-b^{p} p_{t}-a^{s}-b^{s} p_{t}\right]+\varepsilon_{t}
$$

and inserting the agents' demand leads to

$$
\begin{aligned}
& \Delta p_{t+1}=\Phi\left[W_{t}^{f t} a^{f t}\left(E_{t}^{f t}\left(p_{t+1}\right)-p_{t}\right)+W_{t}^{c t} a^{c t}\left(E_{t}^{c t}\left(p_{t+1}\right)-p_{t}\right)\right. \\
& \left.+W_{t}^{c s} a^{c s}\left(E_{t}^{c s}\left(p_{t+1}\right)-p_{t}\right)+a^{p}+b^{p} p_{t}\right]+\varepsilon_{t} .
\end{aligned}
$$

With price expectations one obtains

$$
\begin{aligned}
\Delta p_{t+1}= & \Phi\left[W_{t}^{f t} a^{f t}\left(b^{f t}\left(p_{t}^{*}-p_{t}\right)\right)+W_{t}^{c t} a^{c t}\left(b^{c t}\left(p_{t}-p_{t-1}\right)\right)+W_{t}^{c s} a^{c s}\left(b ^ { c s } \left(p_{t}-\right.\right.\right. \\
& \left.\left.\left.p_{t-1}\right)\right)+a^{p}+b^{p} p_{t}\right]+\varepsilon_{t} .
\end{aligned}
$$

Rearranging provides

$$
\begin{aligned}
\Delta p_{t+1}= & \Phi a^{p}+\Phi b^{p} p_{t}+\Phi a^{f t} W_{t}^{f t}\left(b^{f t}\left(p_{t}^{*}-p_{t}\right)\right)+\Phi a^{c t} W_{t}^{c t}\left(b^{c t}\left(p_{t}-p_{t-1}\right)\right)+ \\
& \Phi a^{c s} W_{t}^{c s}\left(b^{c s}\left(p_{t}-p_{t-1}\right)\right)+\varepsilon_{t} .
\end{aligned}
$$

We define $a=\Phi a^{p}, b=-\Phi b^{p}, \alpha=\Phi a^{f t} b^{f t}, \beta_{1}=\Phi a^{c t} b^{c t}$ and $\beta_{2}=\Phi a^{c s} b^{c s}$ and thus derive the final equation of the model as

$$
\Delta p_{t+1}=a-b p_{t}-\alpha W_{t}^{f t}\left(p_{t}-p_{t}^{*}\right)+\beta_{1} W_{t}^{c t}\left(p_{t}-p_{t-1}\right)+\beta_{2} W_{t}^{c s}\left(p_{t}-p_{t-1}\right)+\varepsilon_{t}{ }^{7}
$$

\section{Empirical methodology and data}

\subsection{Oil prices and the fundamental value of oil}

We use monthly spot prices of crude oil for the Brent blend provided by the Energy Information Administration (EIA). Our sample for oil prices ranges from January 1986 to December 2011 which sums up to 312 observations. ${ }^{8}$ We decided to use monthly data over daily data to get a longer time

\footnotetext{
${ }^{6}$ Again, the model could be extended to nonlinear net demand functions but the main scope of our research is different.

${ }^{7}$ This notably avoids the parameter identification problem that would arise when using the original parameters.

${ }^{8}$ The sample for the construction of the fundamental values is longer, starting in January 1983 and ending in January 2013.
} 
span of oil prices instead of a higher resolution of prices. The use of monthly data is adequate since we can investigate the price expectations of different trader groups over a longer time horizon. Another reason is the lack of daily fundamental data, as for the construction of some fundamental oil values used in our study only monthly or yearly data is available. Using monthly data also ensures proper estimation where effects are not buried in daily noise.

Besides observed oil prices, the fundamental value of oil is crucial for the analysis. Since there is no observable or generally accepted fundamental value of oil and previous research did not show differing results based on different fundamental values, we do so using six approaches: These can be mainly divided into three groups: (i) values related to fundamentally driving oil variables, (ii) values which are based on simple time series techniques and (iii) values which are based solely on theoretical long term considerations of oil price movements. All these fundamental values haven been used in the literature before, yet not in comparison in the context of a study like ours. The details of their construction is explained in the following.

\section{a) Values based on fundamental oil data}

The first value makes use of the results presented in Reitz et al. (2012) and the references therein. The authors argue that mainly three variables describe driving forces for oil prices. First, a variable which reflects an increase in global demand for oil while non-OPEC production could not catch up with this development, represented by the global consumption of oil divided by the oil production in non-OPEC states. We denote this variable as $O_{t}$. Second, a variable that accounts for current market tightness which is reflected by Chinese oil imports and denoted as $C_{t}$. And third, a variable that measures future market tightness which is based on the static reserve-to-production ratio denoted as $R_{t}$.

We use the same data and regression equation as Reitz et al. (2012). Thus, we assume that the fundamental value of oil can be obtained by regressing oil spot prices on the above mentioned fundamental variables:

$$
p_{t}=\kappa_{0}+\kappa_{1} O_{t}+\kappa_{2} C_{t}+\kappa_{3} R_{t}+\varepsilon_{t}
$$

In contrast to Reitz et al. (2012) we estimate two different variants of this value. On the one hand, we run the regression over the whole sample ranging from January 1983 to December 2011. On the other hand we follow the approach by Reitz et al. (2012) and conduct a recursive estimation.

For the recursive estimation we are using the time period from January 1983 to December 1985 first, updating the sample every month by an additional data point. Put differently, agents are using only information available up to time point $t$ when estimating a fundamental value (EFVR).

The approach using all data to the contrary might not be fully valid because then agents use information as if they had perfect foresight regarding the fundamental value. Yet, it gives us the opportunity to compare the results from using the full sample fundamental value (EFV) against the recursively estimated fundamental value. 
Figure 1 gives an impression of the data. Brent crude prices (solid line) are fluctuating around the fundamental value estimated from the full sample (dashed line) and the recursive estimated fundamental value (dotted line). At the end of the sample both fundamental values are equal by construction because the regressions are done using the same information.

It can be seen that it might be difficult to explain the large price swings in 2008 and 2011 by fundamental factors. Naturally, this comes as no surprise given the financial market disruptions from 2008 onwards and this might be the influence of chartists which we want to investigate in this article.

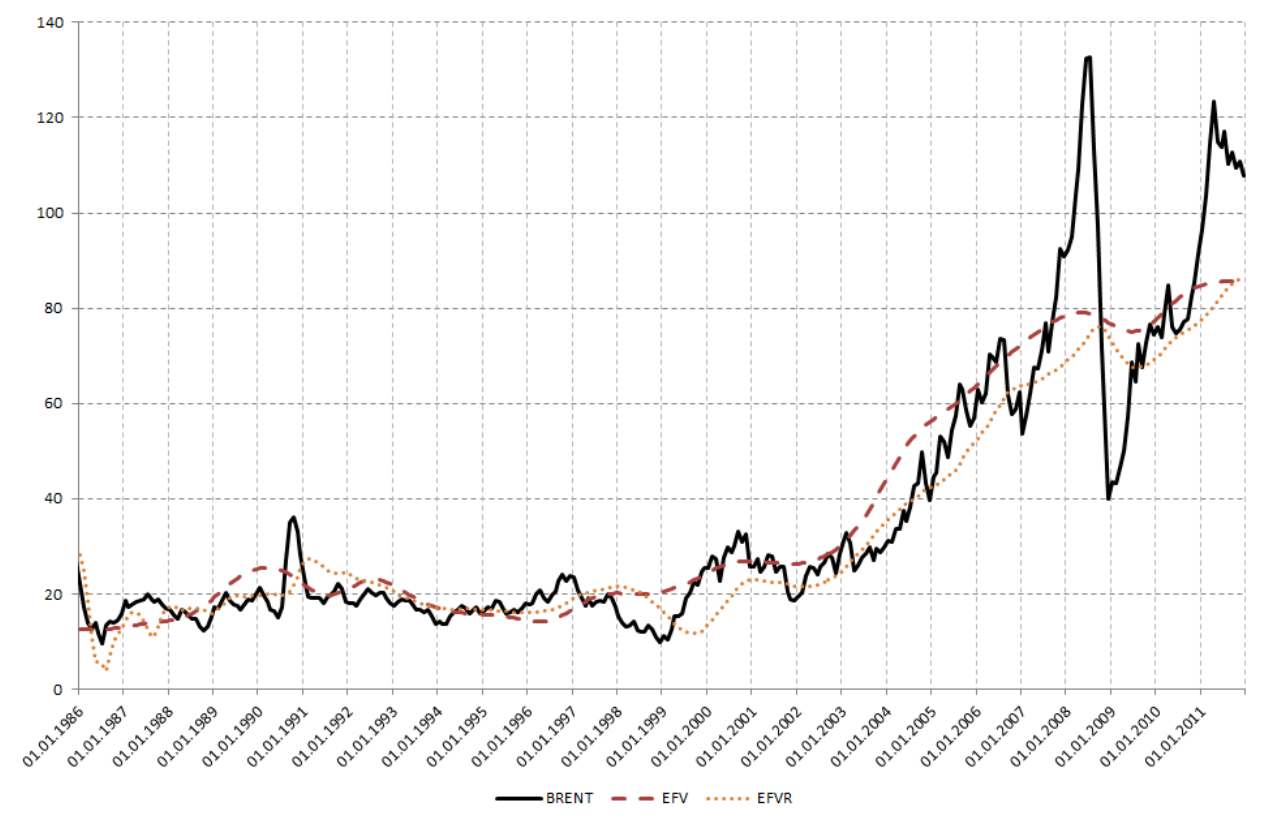

Figure 1: Estimated fundamental value of oil based on fundamental factors

\section{b) Values based on simple time series techniques}

In their article Ellen and Zwinkels (2010) argue that a moving average as proxy for the fundamental value is sufficient since the HAM only needs a value where oil prices revert to. This is fulfilled in the case of a moving average which is computed using 24 months. However, Ellen and Zwinkels (2010) are using a moving average which is not computed using only historical data points but is also forward looking. In detail their moving average, which we want to label as moving average forward looking (MAFL) relies on the last 12 months and the next 12 months at any point of time. Therefore their derived fundamental value shares the feature of the estimated full sample fundamental value of the first group that it is making use of inaccessible information. 


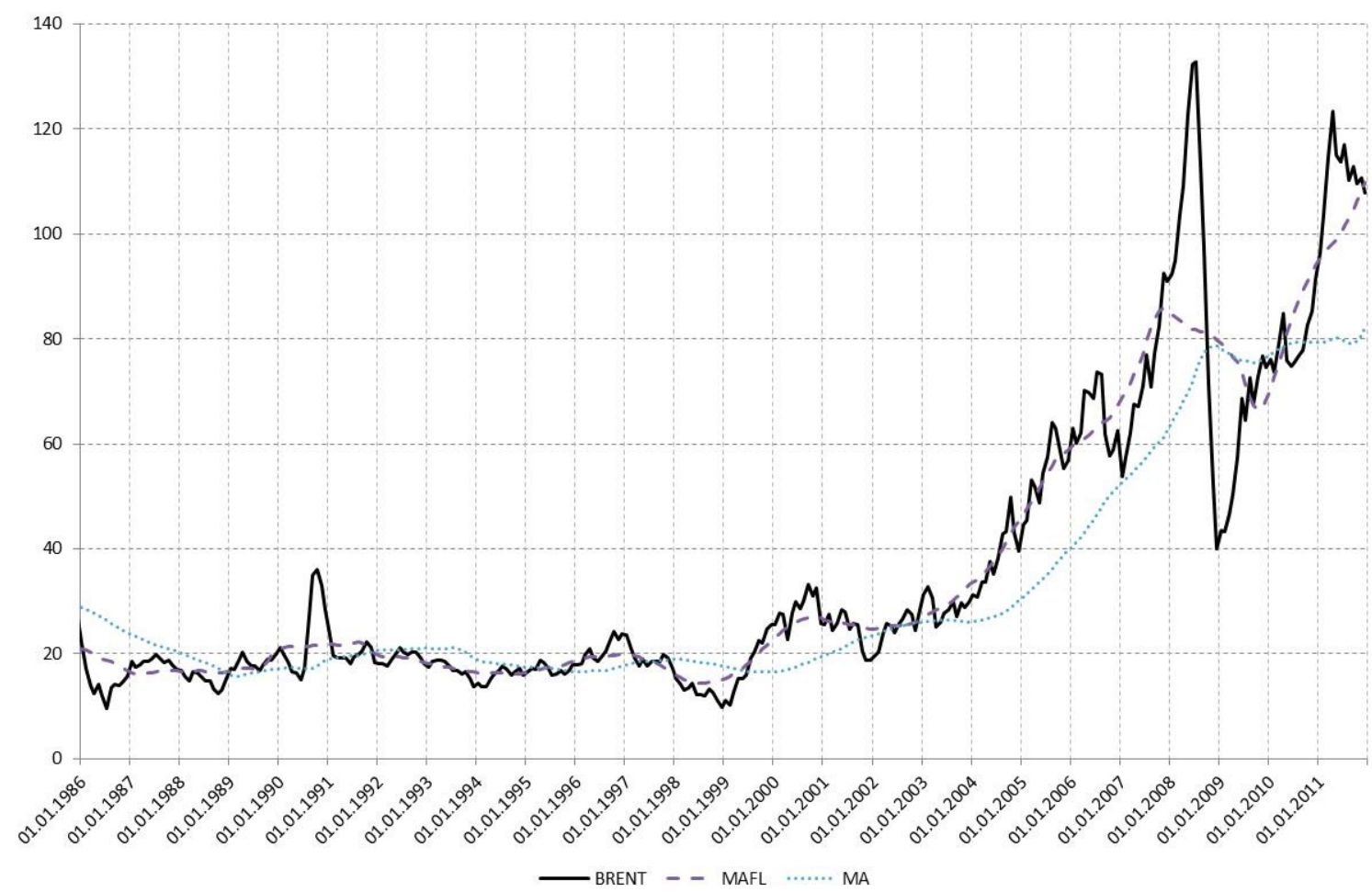

Figure 2: Estimated fundamental value of oil based on time series techniques

Additionally, we are interested in the performance and usefulness of a true moving average (MA). Thus we are also using a true moving average over the last 24 months. From the graphs in Figure 2 it can be seen that the forward looking moving average (dashed line) might be a better candidate since ups and downs are much better reflected instantaneously. The simple moving average (dotted line) shows by definition a more sluggish behavior. Especially during the upward swing between 2004 and 2008 the simple moving average is always below the oil price which makes this value less reliable as a fundamental value, but is still economically more reasonable compared to the one using inaccessible information. In contrast to the values based on fundamental factors, the fundamental values presented here do not converge at the end of the sample period. At the end of the sample period, the MAFL again anticipates oil prices better than the pure moving average.

\section{c) Values based on theoretical long-term considerations}

Pindyck (1999) argues that depletable resources as coal, natural gas or oil are mean-reverting to a quadratic trend line. This quadratic trend line represents long-run total marginal costs of the resource. Since our sample of monthly oil prices is not sufficiently long for estimating the quadratic trend we make use of an additional data set provided in BP (2013). The data set consists of yearly oil prices from 1870 to 2011, thus includes 142 observations. As for the fundamental values estimated before, we follow two different approaches. On the one hand we make use of the whole sample for the estimation of the quadratic trend. On the other hand we estimate a recursive quadratic trend using only data up to 1986 at first and then extending the data set by one data point each year. The results from the regressions are presented in Figure 3. 


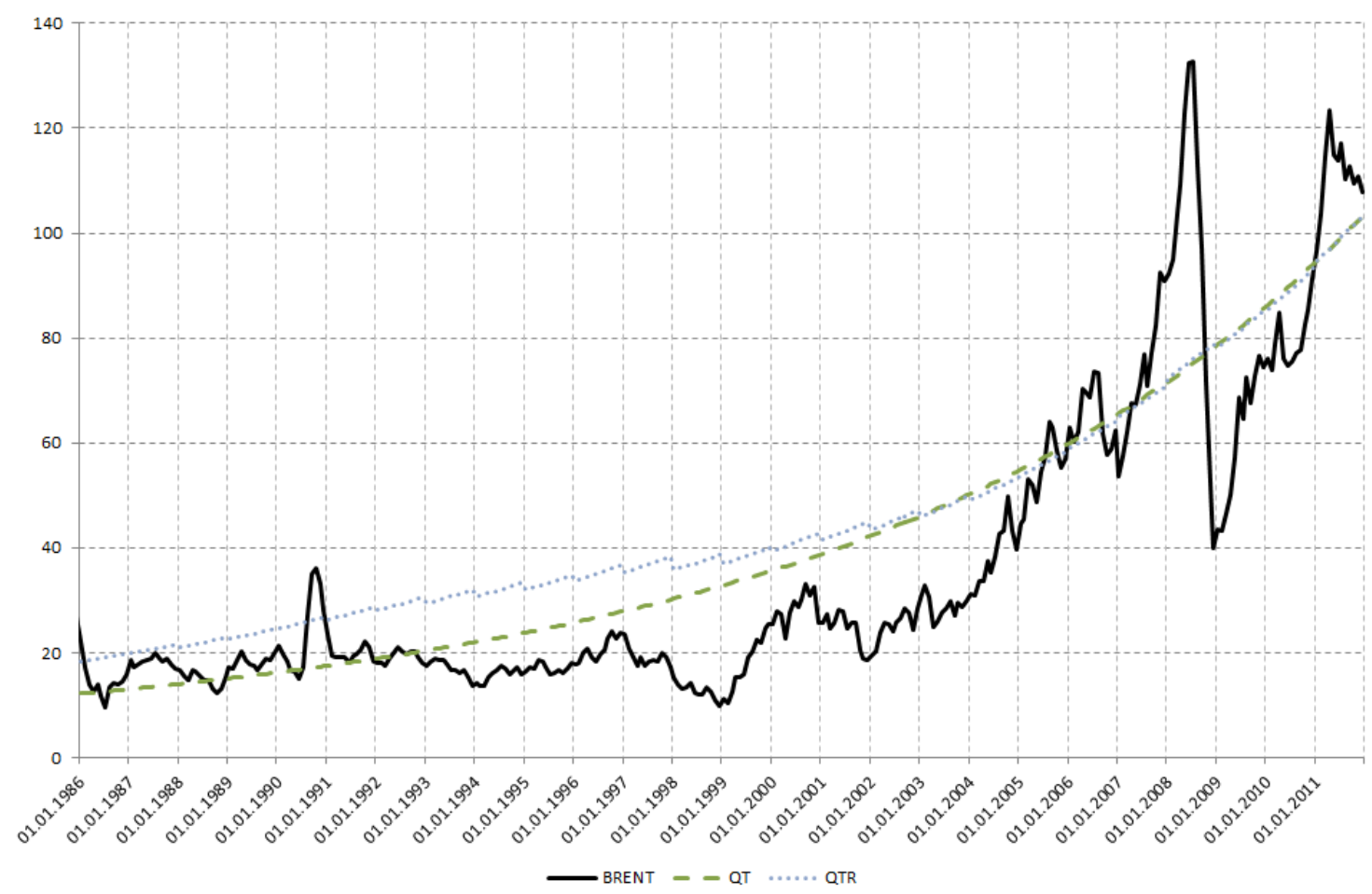

Figure 3: Estimated fundamental value of oil based on theoretical considerations

From the graphical inspection it can be seen that both fundamental values might be candidates for a fundamental value, but oil prices only roughly fluctuate around them. The full sample quadratic trend (dashed line, QT) might be slightly better since oil prices are crossing this value more often than the recursive quadratic trend (dotted line, QTR). Especially in the period from 1993 to 2005 observed oil prices never cross the fundamental values.

Putting all fundamental values together, we end up with six different variants of our general model which have to be estimated. The descriptive statistics for the models in Table 1 are computed from the values of Brent prices minus fundamental value. In terms of root mean squared error, models EFV, MAFL and QT are better than their complement models EFVR, MA and QTR.

Table 1: Descriptive Statistics of oil prices and pricing error of fundamental models

\begin{tabular}{lrrrrr} 
& Mean & Std.Dev. & Max & Min & RMSE \\
\hline Crude Oil & $35,98^{\prime}$ & $28,41^{\prime}$ & $132,72^{2}$ & 9,56 & \\
EFV & $-0,64$ & - & 53,87 & $-37,00$ & 10,70 \\
EFVR & 3,07 & - & 58,95 & $-34,25$ & 11,31 \\
MAFL & 0,09 & - & 50,97 & $-39,91$ & 8,53 \\
MA & 4,01 & - & 60,56 & $-38,67$ & 13,58 \\
QT & $-4,69$ & - & 57,73 & $-38,13$ & 13,54 \\
QTR & $-9,03$ & - & 56,96 & $-38,95$ & 15,74 \\
\hline
\end{tabular}

Note: Values are given in US-Dollars. For the estimated models the values of descriptive statistics are calculated based on the pricing error, i.e. the difference of prices and estimated fundamental values.

This is not surprising because the first group of models is exploiting information which is inaccessible in reality: models EFV, MAFL and QT are anticipating models whereas the other models EFVR, MA and QTR are non-anticipating. As can also be seen, the MAFL as in Ellen and Zwinkels (2010) is superior to 
the other models because RMSE is the smallest. It will be interesting to see how this translates into results. In the next section we focus how we obtain the results in the empirical estimations discussing both numerical issues and economic implications from the forecast evaluation setup.

\subsection{Estimation of the non-linear model for oil price movements}

As can be seen from equation Fehler! Verweisquelle konnte nicht gefunden werden., we have to estimate a non-linear model because of the agents' weights. The problem is in general non-convex, so to avoid being trapped in a local optimum we combine maximum likelihood estimation with a prior grid search. The grid search is done over a reasonable space of parameter value combinations for which the log-likelihood function is evaluated. Parameter sets corresponding to the fifty best likelihood function values are then used as starting values for the optimization algorithm. This means that we run the optimization algorithm fifty times for every model specification. In each case of our six model specifications, the optimization algorithm converges to the same parameter set for all respective starting values. From this, we conclude that we have found the optimal solutions of our model and are not stuck in local optima.

A further difficulty when estimating the models arises from the fact that the number of lags that the agents are using for the evaluation of their forecasting performance is not observable but has to be estimated within the model. Therefore the fitness functions from equations (16), (17) and (18) in combination with the price expectations from (4), (6) and (8) are nested within our optimization algorithm. From a theoretical point of view, this is a true behavioral finance approach in contrast to alternative approaches, where the behavior of agents is calibrated ex-ante: Agents evaluate their own forecasting performance, adapt their formation of price expectations which then has an impact on prices. This feedback loop is different from an estimation approach where strategies are determined ex-ante $^{9}$ (possibly even using the whole sample) and the performance evaluation is separated from the estimation of the model parameters. For each group, lags from one up to twelve months are used. This leads to 1,728 different combinations for the lag specification which have to be tested and evaluated. ${ }^{10}$ We decided to select the model specification based on the Akaike Information Criterion (AIC). Since in every model specification the number of parameters used stays the same, the AIC simplifies to the evaluation of the log-likelihood values. The empirically determined lags are equal for every model specification and set to 7 months for fundamentalists, 6 months for chartists and 6 months for contrarians. ${ }^{11}$ This means that agents evaluate their trading performance over roughly half a year in the past.

\footnotetext{
${ }^{9}$ The main difference with this strategy is that agents do only optimize their own forecast performance but not the overall forecast performance in terms of a good model fit.

${ }^{10}$ One could also possibly argue that agents within each group should rely on the same lag lengths when evaluating their forecasting performance. In this paper different lag lengths are allowed since each price expectation formation is different and hence is assumed to be dependent on the evaluation time horizon.

${ }^{11}$ Actually, the lags which are corresponding to the maximum log-likelihood values differ slightly among the models. Specifications of $5 / 7 / 6$, 7/6/6 and 7/6/6 for models EFV, MA and QT as well as 5/7/2, 6/7/2 and 5/7/5 for models MAFL, EFVR and QTR are proposed. The difference between the log-likelihood values are small and statistically not significant. Thus we decided to use equal lags in each group in view of obtaining comparable results.
} 


\subsection{Parameter Values}

The results for the parameter estimation are presented in Table 2. The parameters for real demand and supply i.e. $a$ and $b$ turn out to be close to zero and are never statistically significant with the exception of model QTR. The fact that the parameters are not significant means that physical supply and demand do not exert an impact on oil prices beyond the one captured in the fundamental model except for the model QTR. While this may have economic reasons, it may be attributed to econometric considerations as well, as the parameter $b$ is the coefficient of a level variable. The parameters for the behavior of fundamentalists and chartists are always highly significant at the hypothesized algebraic signs, with the exception of the parameters for chartists in the model MA which is not significant. The positive signs for $\alpha$ reflect the stabilizing behavior of fundamentalists. The positive values for $\beta_{1}$ are in line with the expectations from Section 2 that chartists show destabilizing behavior. The parameter estimates for contrarians are also significant at the hypothesized negative sign. The negative sign here indicates stabilizing behavior (cf. section 2.5). Overall, the signs are consistent across all specifications of the fundamental value, but differ in magnitude.

Table 2: In-sample estimation results

\begin{tabular}{lcccccccc} 
& $a$ & $b$ & $\alpha$ & $\beta_{1}$ & $\beta_{2}$ & $\gamma$ & LLF & $\mathrm{R}^{2}$ \\
\hline EFV & $-0,0068$ & $-0,0019$ & $0,34 * * *$ & $2,08 * *$ & $-0,54 * *$ & $1,35 * *$ & 332,63 & 0,17 \\
& $(0,27)$ & $(0,25)$ & $(3,65)$ & $(2,62)$ & $(1,97)$ & $(2,39)$ & & \\
EFVR & 0,0053 & $-0,0009$ & $0,16^{* *}$ & $2,12 * * *$ & $-0,64 *$ & $1,15^{* *}$ & 322,78 & 0,12 \\
& $(0,2)$ & $(0,12)$ & $(2,37)$ & $(2,97)$ & $(1,68)$ & $(1,98)$ & & \\
MAFL & $-0,0215$ & $-0,0072$ & $0,64 * *$ & $2,25 * *$ & $-0,67 * *$ & $1,09 * *$ & 344,29 & 0,23 \\
& $(0,88)$ & $(1,01)$ & $(5,37)$ & $(3,76)$ & $(2,1)$ & $(2,73)$ & & \\
MA & $-0,0193$ & $-0,0087$ & $0,22 * *$ & 2,33 & $-0,47$ & 1,71 & 323,36 & 0,12 \\
& $(0,69)$ & $(1,04)$ & $(2,29)$ & $(1,37)$ & $(1,21)$ & $(1,27)$ & & \\
QT & $-0,0083$ & $-0,0017$ & $0,24 * * *$ & $2,34 * * *$ & $-0,23 * *$ & $2,34 * * *$ & 322,25 & 0,11 \\
& $(0,32)$ & $(0,23)$ & $(6,02)$ & $(4,08)$ & $(2,04)$ & $(4,81)$ & & \\
QTR & $-0,1201 * * *$ & $-0,0277 * * *$ & $0,43 * * *$ & $2,15 * *$ & $-0,83 * * *$ & $1,14 * * *$ & 324,96 & 0,13 \\
& $(3,32)$ & $(2,89)$ & $(3,21)$ & $(4,87)$ & $(4,81)$ & $(4,23)$ & & \\
\hline
\end{tabular}

Note: ${ }^{*}$ denotes statistical significance at the $10 \%$ level, $* *$ at the $5 \%$ level, $* * *$ at the $1 \%$ level. $\mathrm{t}$-Values are given in brackets.

In detail, focusing on the fundamentalists' coefficients, we conclude that there are speculative investors in the market that apply a trading strategy based on the deviation of current crude oil prices from fundamental values. The absolute values of the coefficients reveal that the influence of fundamentalists is largest in the model MAFL. From a theoretical point of view this is not surprising, since the MAFL exploits information of the next 12 months as in Ellen and Zwinkels (2010) which should lead to a better performance of fundamental forecasts and hence a greater influence of fundamentalists. The smallest influence is observed in the models MA and EFVR. For the model EFVR this comes as no surprise since information is not available ex-ante as in the model EFV. For the model MA this indicates that the moving average is a poor proxy for a fundamental price as it is rather a technically derived price. Yet, the interpretation of the absolute values of the coefficients is difficult because they are weighted by the function $W_{t}^{h}$ as explained in Section 2 and thus have to be seen in combination.

The presence of chartists is always significant with the exception of model MA and is quite similar across all models. The range of variation across specifications, as measured through the variation 
coefficient, is around 0.049 for the $\beta_{1}$-coefficients. By contrast, the variation coefficient is around 0.515 for the $\alpha$-coefficients. This is linked to the fact that the expectation formation of chartists is similar in all models and their price impact. The definition of the fundamental value however differs strongly between the models and has a huge impact on model results. Hence a sound specification of the fundamental value is primordial; otherwise the overall results of the model are strongly affected not only in terms of model fit but also in terms of economical interpretation. This is goes beyond the statement of Ellen and Zwinkels (2010) that the models need only a fundamental value where prices can revert to. In fact, our results underpin that the fundamental value determines the economic interpretation and is thus not only relevant for technical issues. Reversion of price trends can not only be attributed to the performance of fundamentalists alone but also to the presence of contrarians in the market. As discussed, stabilizing effects induced by fundamentalists and contrarians affect the performance and thus the presence of chartists.

The generally best fitting model is obtained with the model MAFL where a forward looking moving average has been used. This is however not the best model as it is based on an unrealistic information set. Among the three non-anticipating models, none is clearly outperforming the others, although the model QTR based on long-term considerations achieves a slightly higher R-squared and also is the only model that has all significant coefficients.

With regard to the intensity of choice, the parameter $\gamma$ is always positive and significant, again with the exception of model MA. Thus, agents switch indeed between trading strategies. Or at least, the forces driving price dynamics are changing over time. As discussed, the higher the value of $\gamma$, the higher the speed of adaption of a different trading strategy. Agents acting in model QT most rapidly adapt new trading strategies whereas agents of model MAFL have the slowest reaction to performance differences among trading strategies. This is an indicator for the belief in trading strategies, but from the parameters alone we cannot see the dynamics of changes between strategies over time. This is therefore investigated further in the next sub-section.

\subsection{Speculators' behavior}

The behavior of speculators is depicted in the following figures. The monthly weights of fundamentalists, chartists and contrarians are plotted against the price differential between the crude oil price and the model-specific fundamental value. For each month, the shading indicates the speculator group with the highest influence. Fundamentalists are plain white, chartists depicted with dark grey and contrarians light grey. Additionally the weight of chartists is shown as a dashed line. 

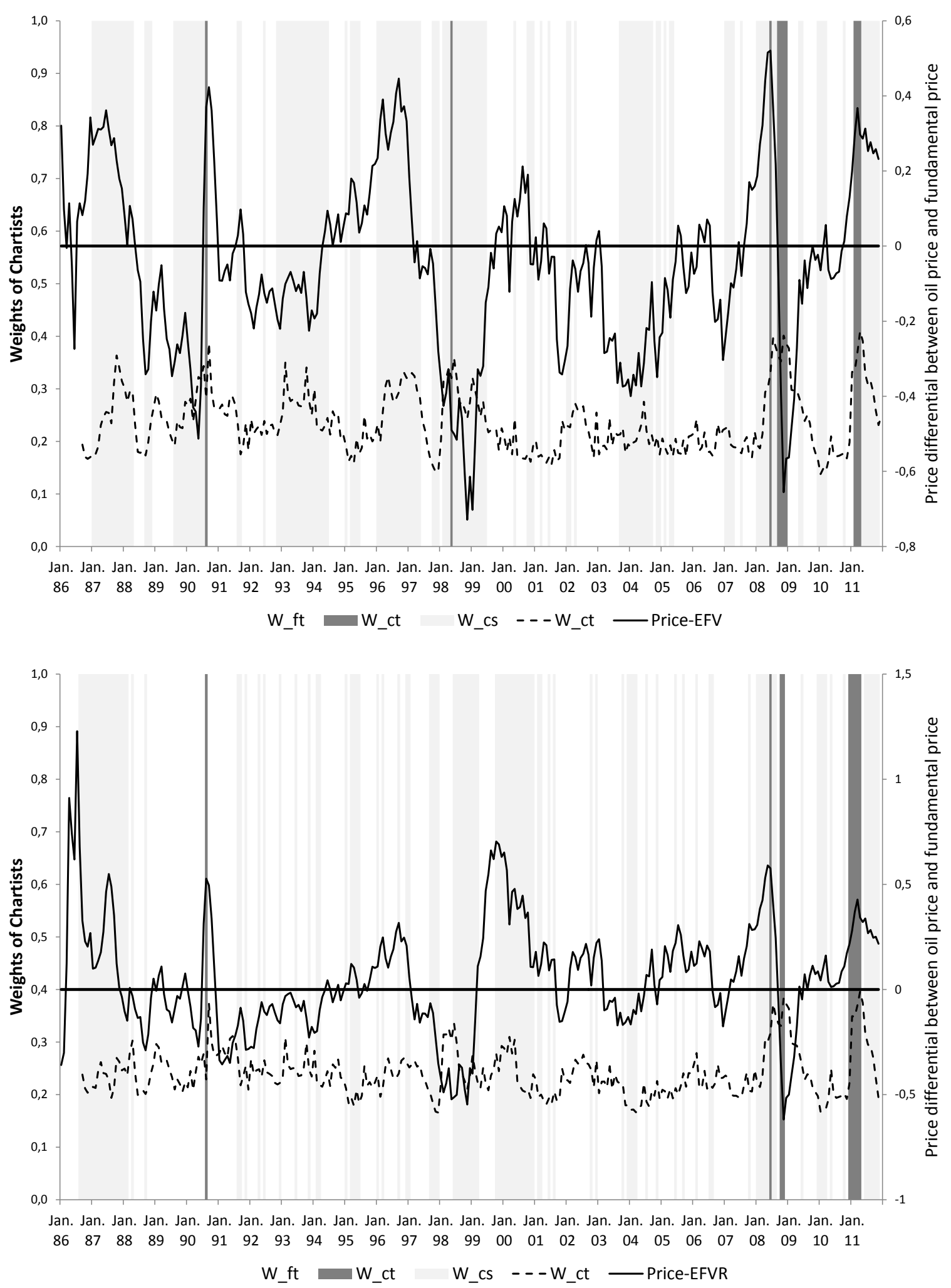

Figure 4: Weights and price differential (fundamental oil data model)

In Figure 4 the weights corresponding to models based on fundamental oil data (EFV, EFVR) are shown. The role of fundamentalists and contrarians differs between the models, in the model EFV contrarians are more frequently the dominating group. Taking both groups as one, because they have both stabilizing behavior, it can be seen that there are only few months where chartists are the most 
important group in the market. In both models this occurs in 1990, 2008 and spring 2011. The weight of chartists (dashed line) in both models indicates that there are at least four periods $(1990,1998$, $2008 / 2009,2011$ ) where the weight of chartists is increasing significantly. This is also coinciding with the largest deviations from the fundamental value. 1990 is the first gulf war, 1998 is the Asian financial crisis with oil prices at a record low, whereas 2008 marks the culmination of the boom in commodities. 2011 might be attributed to the Fukushima catastrophe. The identified periods are almost the same as in Ellen and Zwinkels (2010) with the exception of 1998. Speculative behavior of chartists hence seems not to be dominating in the market over longer periods, but their increasing presence may lead to short-term price distortion.

In Figure 5 the dynamics of trading strategies are shown for the models based on time series techniques (MAFL, MA). The results are rather similar to those of the previous set of models. A slight difference is that in 1998 the weight of chartists does not increase significantly.

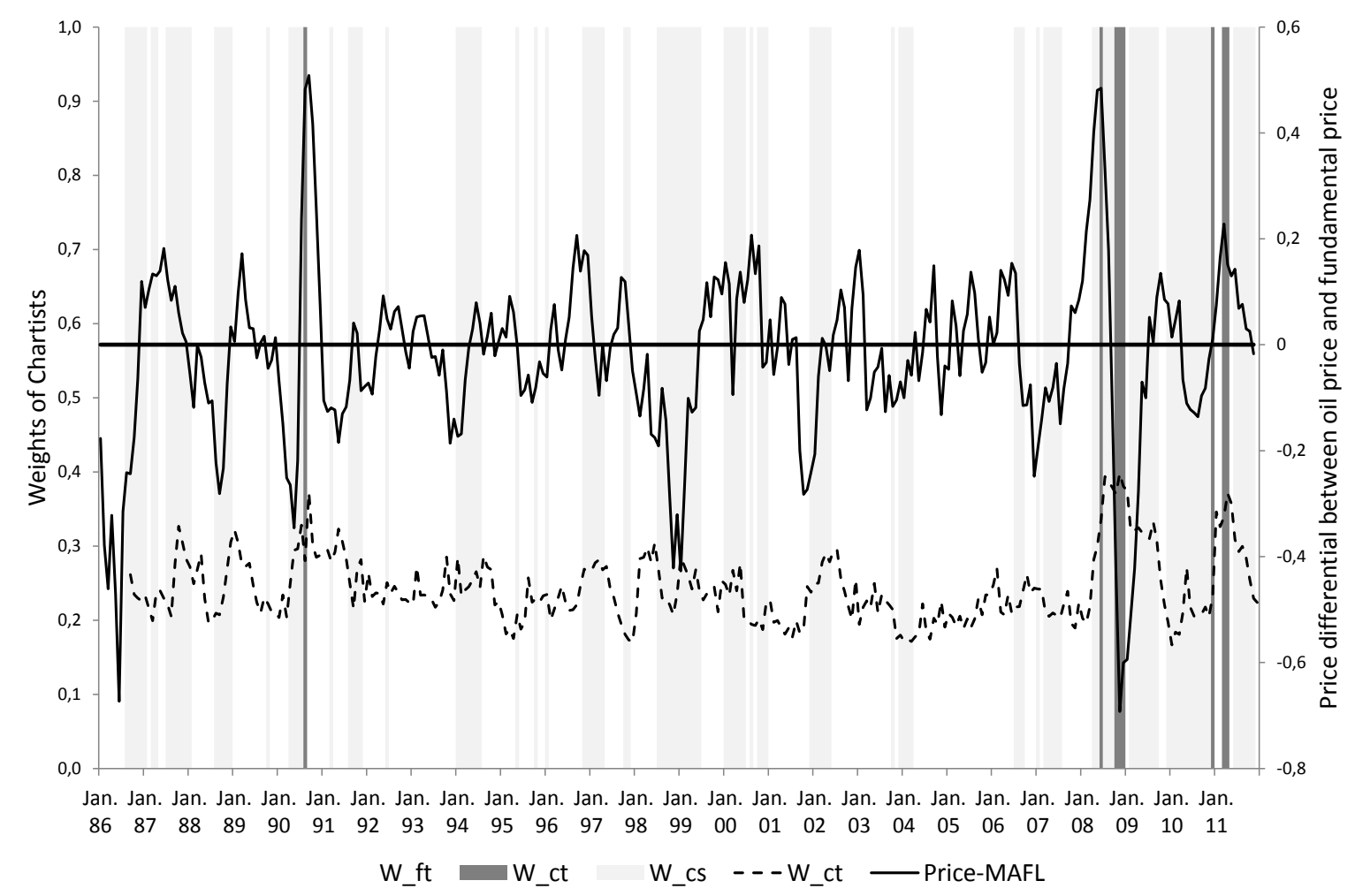




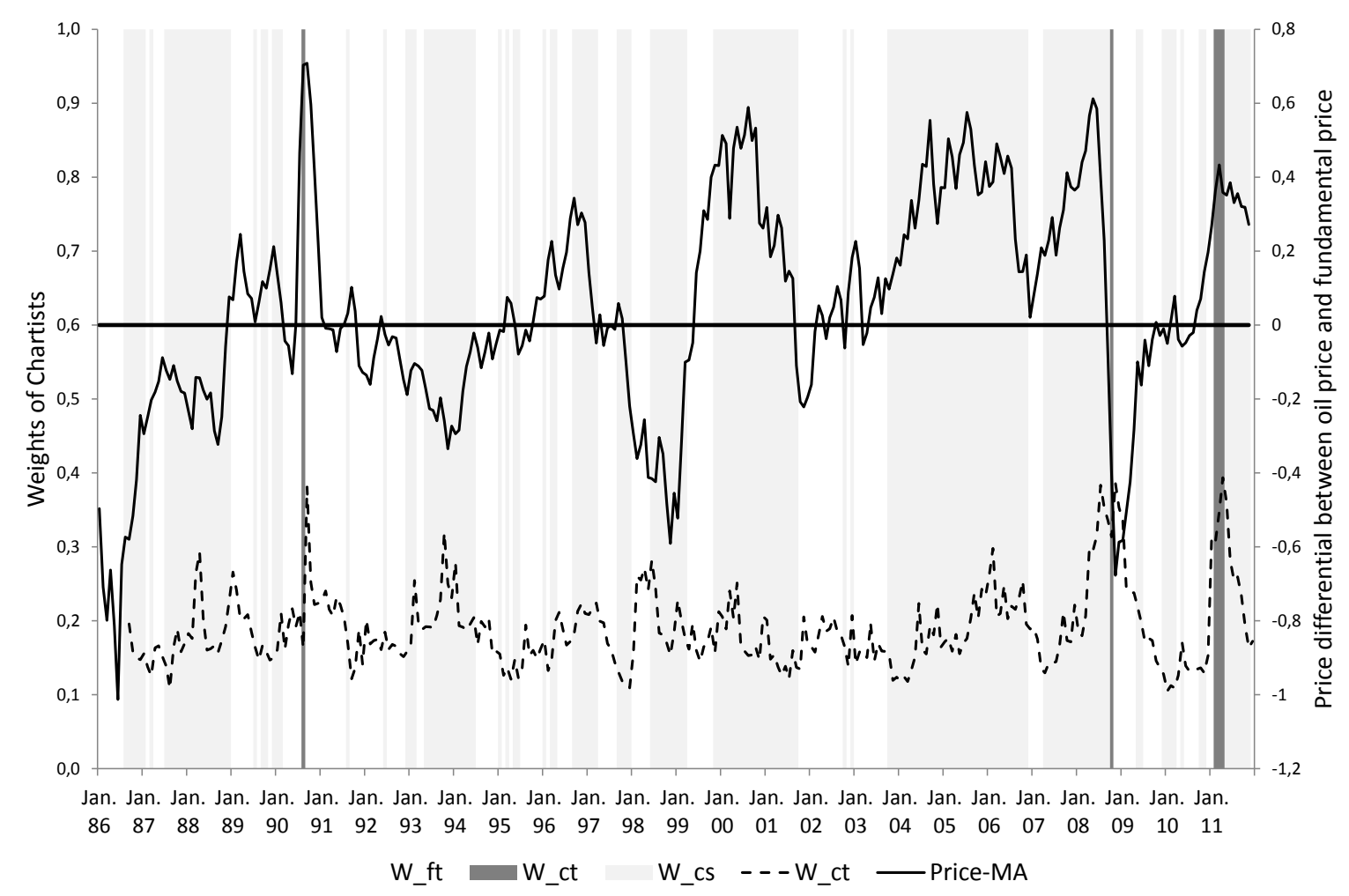

Figure 5: Weights and price differential (time series techniques model)

In Figure 6, the weights of speculator groups are shown for the models based on theoretical considerations (QT, QTR). Again, the behavior of chartists is similar to the previous models. Most of the time, contrarians are the dominating group (during 212 months in model QT and during 232 months in model QTR). This is not too surprising. The time series has 312 observations and during 170 of these months prices exhibit trends of at least two months, whereas in 142 months the price movement is reverting. Since agents evaluate their trading performance over the past half year a lot of trend reversals are not in favor of chartists but in favor of contrarians. Additionally, between 1993 and 2005 the fundamental value never crosses oil prices, making the performance of fundamentalists very poor and hence weakens the belief in their strategy. Correspondingly, the group of fundamentalists is relatively small in models QT and QTR and contrarians tolerate prices moving away from fundamental values which is exacerbated by chartist behavior. Yet, the stabilizing behavior of contrarians dominates in the market with the exception of the periods 1990, 1998-1999, 2008 and 2011 where the number of chartists increases substantially. 

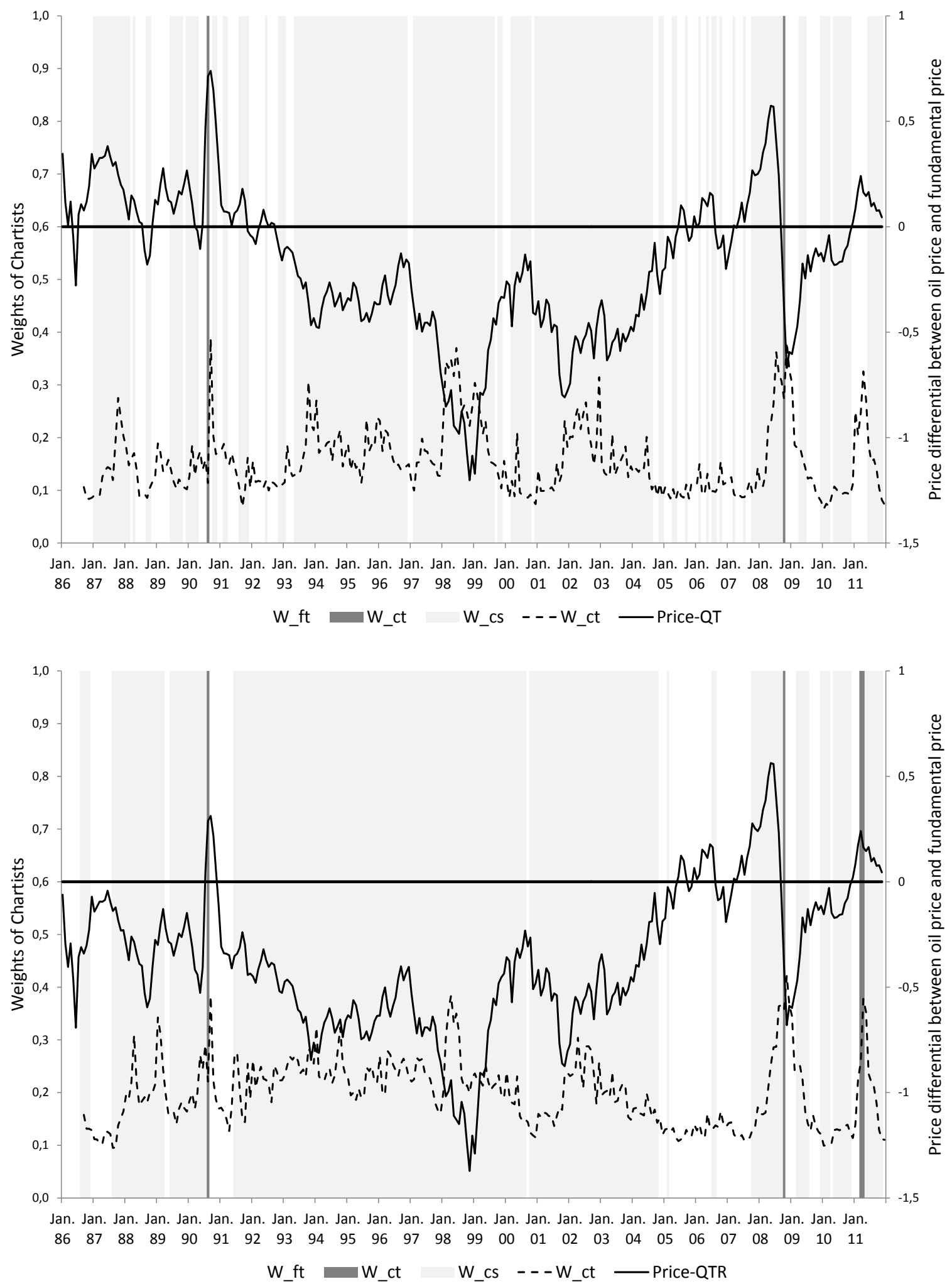

Figure 6: Weights and price differential (theoretical considerations model)

To sum up, the specification of the fundamental value has an impact on the performance of fundamentalists. Contrarians will partly step in instead of fundamentalists to bring prices back to recently observed values, particularly in models with fundamental values far from the actual ones. Chartists on the contrary are found to be the driving forces to bring prices away from fundamental 
values. This does not mean that chartists are destabilizing the market first, but rather that they are following trends which are caused by the behavior of fundamentalists and contrarians.

It can also be concluded that it is not necessary that prices always reflect the fundamental value of the commodity. The self-referential hypothesis as stated by Orlean (2005) assumes that agents react on current prices and also on future market opinions (e. g. forecasts of fundamental values). Even if these values would be available to all agents in the market, they could have different beliefs of the persistence of deviations from the fundamental value. In our model this is expressed by the evaluation of trading performance (fitness measure). In the end this leads to fundamental traders tolerating large deviations from the fundamental value. Their behavior can be still considered as fully rational. However, Barberis and Thaler (2003) state that deviations from fundamental values are caused by agents which are not fully rational. This is contradictory to our statement. We believe that fundamentalists, chartists and contrarians are aware of the fundamental value but that they have different beliefs (for example chartists and contrarians not taking the fundamental value into account) based on their performance in the past, thus still acting fully rational.

\subsection{Further Analysis of Weights}

Table 3 represents the descriptive statistics for the weights in the different trading groups. In contrast to the model of Ellen and Zwinkels (2010) there are never more than $50 \%$ of chartists in the market. The group of contrarians has the smallest standard deviation. This is an indication that the persistence of the trading strategy among the contrarians is quite high and a lot of trend reversals are in favor of contrarians.

Table 3: Descriptive statistics of weights

\begin{tabular}{lllllr} 
& & Min & Mean & Max & Std. Dev. \\
\hline EFV & W_ft & 0,19 & 0,37 & 0,46 & 0,06 \\
& W_ct & 0,14 & 0,24 & 0,41 & 0,06 \\
& W_cs & 0,27 & 0,39 & 0,48 & 0,04 \\
\hline EFVR & W_ft & 0,28 & 0,39 & 0,43 & 0,03 \\
& W_ct & 0,17 & 0,24 & 0,40 & 0,04 \\
& W_cs & 0,27 & 0,38 & 0,44 & 0,03 \\
\hline MAFL & W_ft & 0,22 & 0,38 & 0,43 & 0,04 \\
& W_ct & 0,17 & 0,24 & 0,40 & 0,05 \\
& W_cs & 0,28 & 0,38 & 0,45 & 0,03 \\
\hline MA & W_ft & 0,21 & 0,39 & 0,49 & 0,05 \\
& W_ct & 0,10 & 0,19 & 0,39 & 0,05 \\
& W_cs & 0,28 & 0,42 & 0,50 & 0,04 \\
\hline QT & W_ft & 0,15 & 0,38 & 0,55 & 0,09 \\
& W_ct & 0,06 & 0,15 & 0,39 & 0,06 \\
& W_cs & 0,28 & 0,47 & 0,58 & 0,05 \\
\hline QTR & W_ft & 0,10 & 0,27 & 0,66 & 0,15 \\
& W_ct & 0,09 & 0,20 & 0,42 & 0,06 \\
& W_cs & 0,22 & 0,53 & 0,71 & 0,13 \\
\hline
\end{tabular}


As mentioned before, the specification of the fundamental value directly influences the behavior of fundamentalists and indirectly the behavior of contrarians. This is underpinned when looking at the correlations between the weights within a speculator group and across the models. The largest correlations occur in the group of chartists and contrarians whereas the correlations in the group of fundamentalists are smaller and sometimes even close to zero. This shows that the different models are mostly able to identify similar periods where chartists and contrarians are active in the market but the model specification strongly influences the identification of periods where fundamentalists are active.

Table 4: Correlations of weights

Fundamentalists

\begin{tabular}{|c|c|c|c|c|c|c|}
\hline & $E F V$ & $E F V R$ & MAFL & $M A$ & $Q T$ & QTR \\
\hline EFV & 1 & & & & & \\
\hline EFVR & 0,47681738 & 1 & & & & \\
\hline MAFL & 0,49253153 & 0,52658121 & 1 & & & \\
\hline MA & 0,37532652 & 0,62148949 & 0,35656887 & 1 & & \\
\hline QT & 0,48216517 & 0,22477482 & 0,20911332 & 0,1151986 & 1 & \\
\hline QTR & 0,32424695 & 0,06737466 & 0,03167795 & 0,07956707 & 0,55522521 & 1 \\
\hline \multicolumn{7}{|c|}{ Chartists } \\
\hline & $E F V$ & $E F V R$ & MAFL & $M A$ & $Q T$ & QTR \\
\hline EFV & 1 & & & & & \\
\hline EFVR & 0,83029854 & 1 & & & & \\
\hline MAFL & 0,83270616 & 0,89874979 & 1 & & & \\
\hline MA & 0,77267104 & 0,89927225 & 0,81504194 & 1 & & \\
\hline QT & 0,74168961 & 0,6817404 & 0,65475773 & 0,64184992 & 1 & \\
\hline QTR & 0,70077237 & 0,68479383 & 0,6055942 & 0,60038411 & 0,75490804 & 1 \\
\hline \multicolumn{7}{|c|}{ Contrarians } \\
\hline & $E F V$ & $E F V R$ & MAFL & $M A$ & $Q T$ & QTR \\
\hline EFV & 1 & & & & & \\
\hline EFVR & 0,86459377 & 1 & & & & \\
\hline MAFL & 0,83241695 & 0,89210071 & 1 & & & \\
\hline MA & 0,81697332 & 0,90869934 & 0,82133797 & 1 & & \\
\hline QT & 0,72575641 & 0,64627017 & 0,61291554 & 0,57620597 & 1 & \\
\hline QTR & 0,50590085 & 0,402528 & 0,33799578 & 0,30524949 & 0,64713289 & 1 \\
\hline
\end{tabular}

\section{Conclusion}

The debate about speculators in oil markets in combination with the financialization of commodity markets has been a motivation for this study. Overall, our results indicate that oil market prices are driven by different groups of speculators, namely fundamentalists, chartists and contrarians. Our introduction of contrarians as a third group served us well in disentangling purely trend-reversal 
speculation from reversals to a fundamental value. This is due to the contrarians inducing a trading strategy which is justified by contradicting behavior compared to chartists (trend followers).

Strong and economically reasonable influences of chartists have been found in 1990, 2008 and 2011, independently of the model specification. This result underpins the model results by Ellen and Zwinkels (2010). Our model has also been enhanced by six different specifications of fundamental values of oil. The model specifications for the fundamental values split up into two groups namely anticipative (forward looking) and non-anticipative models and our results show that this distinction is crucial both in terms of goodness of fit and impact on trading strategies. Anticipative model specifications, and this might come as no surprise, are superior to the non-anticipative specifications. However results regarding trading strategies are as far as possible robust independent of model specifications but the specification is still relevant for the overall behavior of fundamentalists and also for contrarians.

In fact, contrarians are the speculator group with the highest share on average among all speculators, showing the importance of the addition to a heterogeneous agent model. The reasoning behind is, that contrarians are also stabilizing in markets and might become active in trading if fundamentalists do not believe in prices going back to their fundamental value and the time series has a lot of trend reversals. However, the huge price swings in 1990, 2008 and 2011 can only be explained by price exacerbation of chartists. This result is in line with the findings of Alquist and Gervais, 2013 and Fattouh et al. , 2013 that the price surge and collapse in the 2000 to 2008 period can essentially be explained by fundamental factors. This result differs from Ellen and Zwinkels (2010) because chartists are not the cause but they might boost the effect of huge price swings. This is common to financial products influenced by chartist speculative behavior.

To sum up, the study has shown that the specification of the fundamental value in heterogeneous agents models and the inclusion of contrarians as a new group of speculators both strongly impact the economic interpretation of speculative behavior in oil markets. The analyses also indicate that chartists are in few periods the most dominating group and that they are not the cause but part of the effect. The inclusion of different switching parameters or an optimization where agents do optimize the overall forecast performance might be a worthy investigation in future research. Moreover, a more detailed modeling of producers and consumers, e. g. an impact on spot crude oil prices dependent on futures prices, or a time dependent parameter in the fitness measure might be also interesting in future research. Also generalizing the model to allow for phases where two strategies point in the same direction, for example during a downturn in prices after a phase of overvaluation and thus both fundamentalists and chartists being active, might be of interest. 


\section{References}

Alquist, R., Gervais, O., 2013. The Role of Financial Speculation in Driving the Price of Crude Oil, The Energy Journal 3, 35-54.

Barberis, N., Thaler, R., 2003. A Survey of Behavioral Finance, in: Constantinidis, G. M., Harris, M., Stulz, R. (Eds.), Handbook of the Economics of Finance, 1052-1121.

Boswijk, H. P., Hommes, C. H., Manzan, S., 2007. Behavioral heterogeneity in stock prices, Journal of Economic Dynamics and Control 6, 1938-1970.

BP, 2013. BP Statistical Review of World Energy. http://www.bp.com/en/global/corporate/aboutbp/energy-economics/statistical-review-of-world-energy.html.

Brock, W., Hommes, C. H., 1997. A Rational Route to Randomness, Ecometrica, Journal of the Econometric Society 5, 1059-1095.

Brock, W., Hommes, C. H., 1998. Heterogeneous beliefs and routes to chaos in a simple asset pricing model, Journal of Economic Dynamics and Control 8-9, 1235-1274.

Ellen, S. t., Zwinkels, R. C., 2010. Oil price dynamics: A behavioral finance approach with heterogeneous agents, Energy Economics 6, 1427-1434.

Fama, E. F., 1970. Efficient Capital Markets - Review Of Theory And Empirical Work, The Journal of Finance 2, 383-423.

Fattouh, B., Kilian, L., Mahadeva, L., 2013. The Role of Speculation in Oil Markets: What Have We Learned So Far?, The Energy Journal 3, 7-33.

Greenspan, A., 2004. Testimony of Chairman Alan Greenspan. http://www.federalreserve.gov/boarddocs/testimony/2004/200409082/default.htm.

IEA (International Energy Agency), 2013. Key World Energy Statistics, Paris.

Kaufmann, R. K., Ullman, B., 2009. Oil Prices, Speculation, and Fundamentals: Interpreting Causal Relations Among Spot and Futures Prices, Energy Economics 4, 550-558.

Lof, M., 2012. Heterogeneity in stock prices: A STAR model with multivariate transition function, Journal of Economic Dynamics and Control 12, 1845-1854.

Lof, M., 2015. Rational Speculators, Contrarians and Excess Volatility, Management Science 8, 18891901.

Orlean, A., 2005. The self-referential hypothesis in finance, Paris School of Economics.

Pindyck, R. S., 1999. The Long-Run Evolution of Energy Prices, Energy Journal 2, 1-27.

Reitz, S., Rülke, J.-C., Stadtmann Georg, 2012. Nonlinear Expectations in Speculative Markets, Journal of Economic Dynamics \& Control 36, 1349-1363.

Reitz, S., Slopek, U., 2009. Non-Linear Oil Price Dynamics: A Tale of Heterogeneous Speculators?, German Economic Review 3, 270-283.

Reitz, S., Westerhoff, F. H., 2007. Commodity Price Cycles and Heterogeneous Speculators: a STARGARCH Model, Empirical Economics 2, 231-244. 
Sornette, D., Woodard, R., Zhou, W.-X., 2009. The 2006-2008 oil bubble: Evidence of speculation, and prediction, Physica A: Statistical Mechanics and its Applications 8, 1571-1576. 
